\title{
Simplified approach to the design of segmental tunnel linings
}

Ngoc Anh Do PhD

Dean of Faculty, Sustainable Development in Underground Engineering Group, Department of Underground and Mining Construction, Faculty of Civil Engineering, Hanoi University of Mining and Geology, Vietnam

Daniel Dias PhD

Distinguished professor, School of Automotive and Transportation Engineering, Hefei University of Technology, Hefei, China; Professor, Laboratory 3SR, Grenoble Alpes University, Grenoble, France (corresponding author: daniel.dias@ujf-grenoble.fr)
Pierpaolo Oreste PhD

Professor, Department of Environmental, Land and Infrastructural Engineering, Politecnico di Torino, Turin, Italy

A new simplified approach to the hyperstatic reaction method (HRM) for the analysis of segmental tunnel linings is introduced. The influence of segmental joints on the lining behaviour is taken into account by considering opening/rotation of the joints under external loads, which cause a reduction in the contact surface area between two segments at the joint location and certain surrounding zones. Consequently, a decrease in the inertial modulus and cross-sectional area at these sections of the lining ring is expected. A specific implementation was developed using a finite-element method framework in which an iterative procedure was applied with the height of the joint section as the unknown parameter. The results obtained using the new simplified HRM (SHRM) were compared with those obtained using the existing complex HRM, which takes joints directly into account, and a three-dimensional numerical model. The results obtained show that the SHRM can be used to estimate the behaviour of a segmental tunnel lining effectively.

Notation
$A_{\mathrm{s}}$
$B$
$b_{\mathrm{c}}$
$b_{\mathrm{j}}$
$b_{1}$
$E_{\mathrm{c}}$
$E_{\mathrm{s}}$
$E_{\mathrm{j}}^{\mathrm{i}}$
$F_{1}, F_{2}, F_{3}, \ldots, F_{n}$

area of transversal section

width of a lining ring $(\mathrm{m})$

width of concrete section $(\mathrm{m})$

width of joint section $(\mathrm{m})$

width of lining ring $(\mathrm{m})$

Young's modulus at concrete section

elastic modulus

Young's modulus at joint section

sub-vectors composed of the three external

forces applied to each node in the global

Cartesian reference system

$J_{\text {concrete }} \quad$ inertial modulus of concrete section $\left(\mathrm{m}^{4}\right)$

$J_{\text {joint }}$

$J_{\mathrm{s}}$

$\mathbf{K}$

$\mathbf{k}_{i}$

$k_{i, a}, k_{i, b}, k_{i, c}, k_{i, d}$

$k_{\mathrm{n}}, k_{\mathrm{s}}$

$L_{i}$

M

$\boldsymbol{M}_{\mathrm{c}}$

$M_{\mathrm{j}}$

$N$

$N_{\mathrm{j}}$ $\boldsymbol{q}$

$q_{1}, q_{2}, q_{3}, \ldots, q_{n} \quad$ sub-vectors composed of the three displacements of each node in the global Cartesian reference system

$\boldsymbol{q}_{\mathrm{v}}, \boldsymbol{q}_{\mathrm{h}} \quad$ applied active loads

$R \quad$ tunnel radius

$S_{\mathrm{j}} \quad$ height of contact section between two

segments at the joint location (m)

$S_{1} \quad$ height of concrete section (m)

$S_{\text {total }} \quad$ average height of cross-section (m)

$\mathbf{z}_{i} \quad$ local stiffness matrix of $i$ th element

$\omega \quad$ angle measured counterclockwise from tunnel bottom

\section{Introduction}

Due to the presence of joints, the behaviour of segmental tunnel linings is different from that of continuous linings (Arnau and Molins, 2012; Do et al., 2013). In the literature, the effects of segmental joints on tunnel lining behaviour have usually been considered indirectly or directly, using analytical, empirical and numerical methods. In indirect methods, the tunnel structure is perceived as a rigid lining ring (Duddeck and Erdmann, 1982; Einstein and Schwartz, 1979; Muir Wood, 1975; Oreste, 2007; Takano, 2000; Zhang et al., 2014). The effect of joints is usually taken into account through a reduced rigidity of the tunnel structure. As far as direct methods are concerned, segmental joints are added directly to the tunnel lining structure and joints are explicitly considered in the analysis (Arnau and Molins, 2012; Blom, 2002; Ding et al., 2004; Do et al., 2013; Lee et al., 2002; Naggar and Hinchberger, 


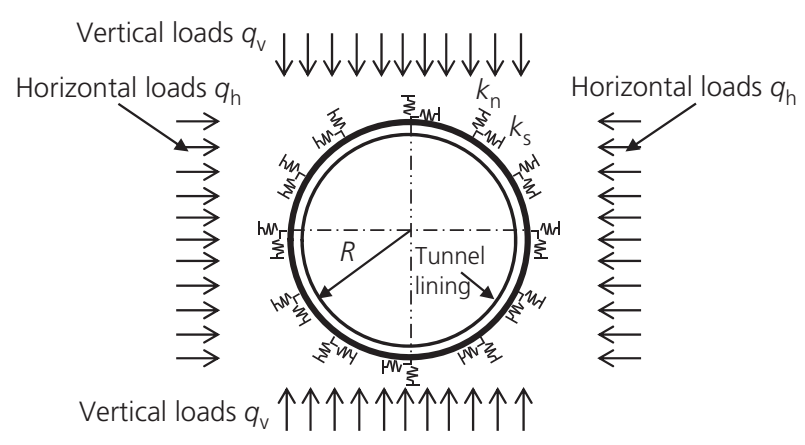

Figure 1. Schematic illustration of support structures adopted in the HRM (from Do et al., 2014a)

2008). A summary of the design methods used for segmental tunnel linings is given by Do et al. (2014a, 2014b).

Do et al. (2014a) developed a new numerical approach to the hyperstatic reaction method (HRM) (Figure 1), referred to as the complex HRM in this paper. In that work, segmental joints were added directly in the HRM. The effect of joints was considered using a fixity ratio that is estimated on the basis of the rotational stiffness. This method allows the threedimensional (3D) effects of segment joints in successive rings on tunnel lining behaviour to be taken into account. In addition, it also allows an arbitrary distribution of segment joints in the lining rings to be simulated. A comparison of the numerical results obtained with the HRM and experimental data obtained from a shield-driven tunnel project showed that the HRM could be used to estimate the behaviour of a segmental tunnel lining effectively within a short calculation time.

A new simplified model of the HRM, hereafter called the SHRM, which allows the influence of joints on the behaviour of segmental tunnel linings to be analysed in another way is presented in this paper. Unlike the existing (complex) HRM proposed by Do et al. (2014a), in the SHRM, the influence of segmental joints is taken into account by considering the reduction of the contact surface and therefore the inertial modulus at lining sections that are influenced by joints. The applicability of the SHRM was analysed through comparisons with both the existing complex HRM and 3D numerical analysis.
The SHRM can be applied using a common HRM calculation method in order to consider the presence of joints in a segmental lining. In this way, without having to use specific and complex computing systems, anyone is able to analyse the mechanical behaviour of segmental linings and proceed to their dimensioning in a simple and effective way. This innovation allows quick analysis of the mechanical behaviour of segmental linings, taking into account all the relevant aspects, including the 3D effect of the presence of adjacent rings with a different joint arrangement.

\section{Mathematical formulation of the HRM}

The numerical HRM for continuous linings was developed by Oreste (2007) and the method was extended for the analysis of segmental tunnel linings by Do et al. (2014b). Therefore, only a short overview is given here.

In the HRM, the support structure is represented by monodimensional elements that are able to develop bending moments, axial forces and shear forces (Oreste, 2007). A beam element $i$ is defined by the inertial modulus $\left(J_{\mathrm{s}}\right)$ and area $\left(A_{\mathrm{s}}\right)$ of the transversal section, the elastic modulus $\left(E_{\mathrm{s}}\right)$ of the constituent material and the length $\left(L_{i}\right)$ (distance between terminal nodes). The interaction between the tunnel structure and surrounding ground is taken into consideration in two ways: through normal and tangential springs connected to the nodes of the structure and through applied active loads $\left(\boldsymbol{q}_{\mathrm{v}}\right.$ and $\left.\boldsymbol{q}_{\mathrm{h}}\right)$ (Figure 1).

The local stiffness matrix $\mathbf{z}_{i}$ of the $i$ th element, which is evaluated according to a local reference system, is transferred to the local stiffness matrix $\mathbf{k}_{i}$ in the global Cartesian reference system before being assembled in the global stiffness matrix, $\mathbf{K}$, using the principal illustrated by Huebner et al. (2001).

Due to the presence of normal and tangential node springs (see Figure 1) along the tunnel structure, modifications of the corresponding elements along the diagonal of the global stiffness matrix $\mathbf{K}$ in terms of the stiffness of the normal springs $\left(k_{\mathrm{n}}\right)$ and shear springs $\left(k_{\mathrm{s}}\right)$ of each node were made (Do et al., 2014b).

The unknown parameters that need to be estimated are the displacement components of the nodes of the discretised structure. The vector $\boldsymbol{q}$ of the nodal displacement components

Global stiffness matrix $\mathbf{K}$ of the segmental lining 
obtained from Equation 1 allows the stresses at the nodes of the structure to be determined (Huebner et al., 2001).

\section{The new SHRM}

A segmental tunnel lining is a 3D structure in which longitudinal joints in successive lining rings are usually staggered along the longitudinal tunnel direction (Figure 2). In order to take into consideration the 3D effect of a segmental tunnel lining, a section, including two halves of two successive lining rings, is considered in the SHRM (Figure 2).

While a fixity factor (Monforton and $\mathrm{Wu}, 1963$ ) was added to the stiffness matrix of each finite element in order to reflect the semi-rigid joint connections between segments in the research conducted by Do et al. (2014a), the fundamental aspect of the proposed SHRM is the assumption that the presence of longitudinal joints in lining rings causes a reduction in the crosssectional area and the inertial modulus of the lining at this section. In other words, the influence of joints can be taken into consideration on the basis of the contact condition of the joint surface between two segments as follows.

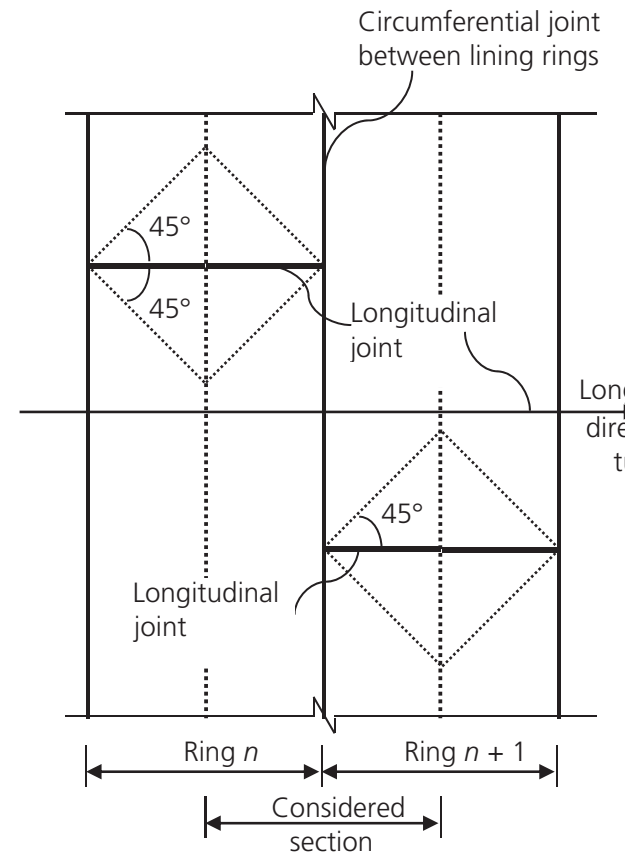

(a)

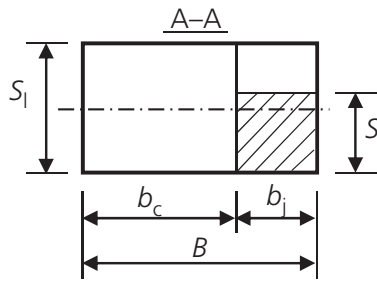

- For a closed surface joint, the joint works as a concrete section without influence on the behaviour of the tunnel lining.

- For an opened surface joint, the joint causes a reduction in the cross-section and inertial modulus of the lining and therefore has a significant influence on the behaviour of the tunnel lining.

It is assumed that each opened joint causes an effect zone as indicated in Figures 2(a) and 2(b).

As shown in Figure 2, the presence of a longitudinal joint weakens the lining at a particular point and this effect is perceived also in neighbouring areas, whereas a dispersion effect of the discontinuity is considered with straight lines inclined at $45^{\circ}$ with respect to tunnel perimeter. In practice, it is assumed that the effect of weakening of the longitudinal joint reduces with distance from the longitudinal joint due to the cooperation of the closest rings where a filled concrete section is present. The dispersion according to $45^{\circ}$ inclined lines is generally considered in stress transfer problems inside concrete structures.

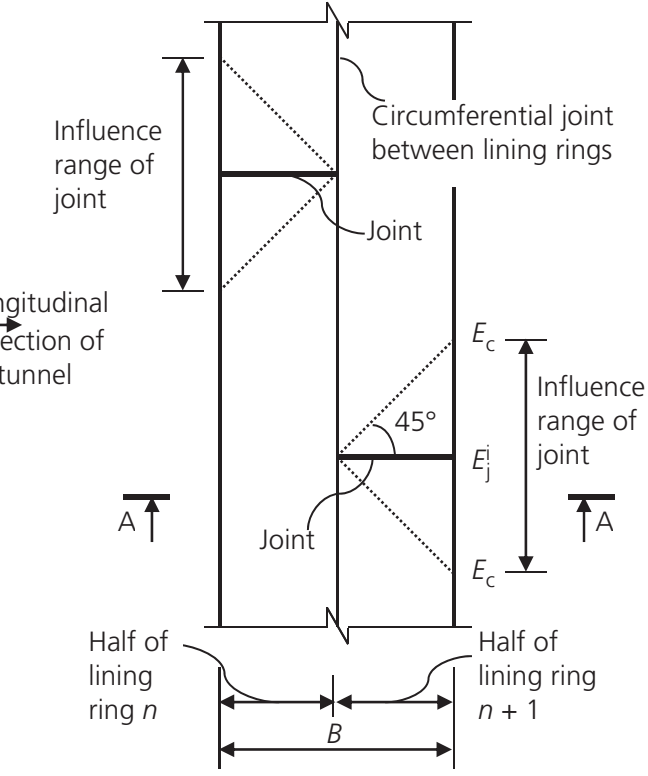

(b)

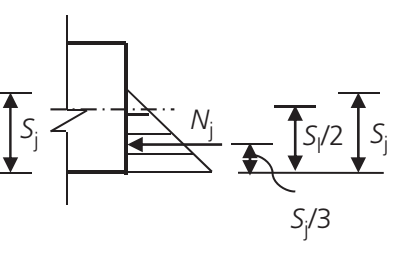

(c)

Figure 2. Segmental lining scheme in the SHRM: (a) true segmental tunnel lining; (b) simplified model in the SHRM; (c) cross-section A-A 
The inertial modulus of a section $\left(J_{\mathrm{s}}\right)$ affected by a joint is the sum of the inertial moduli of the concrete part $\left(J_{\text {concrete }}\right)$ and the joint part $\left(J_{\text {joint }}\right)$ in the section, given by

2. $J_{\mathrm{s}}=J_{\text {concrete }}+J_{\text {joint }}=\frac{b_{\mathrm{c}} S_{1}^{3}}{12}+\frac{b_{\mathrm{j}} S_{\mathrm{j}}^{3}}{12}=\frac{b_{1} S_{\text {total }}^{3}}{12}$

The transversal section area $\left(A_{\mathrm{s}}\right)$ at a lining section, which is affected by a joint, is estimated to be

3. $A_{\mathrm{s}}=b_{\mathrm{c}} S_{\mathrm{l}}+b_{\mathrm{j}} S_{\mathrm{j}}$

The bending moment of each cross-section of a lining ring, $\boldsymbol{M}$, is equal to the sum of the bending moments induced in the concrete part $\left(\boldsymbol{M}_{\mathrm{c}}\right)$ and in the joint part $\left(\boldsymbol{M}_{\mathrm{j}}\right)$

4. $M=M_{\mathrm{c}}+M_{\mathrm{j}}$

From Equations 2 and $4, \boldsymbol{M}_{\mathrm{c}}$ and $\boldsymbol{M}_{\mathrm{j}}$ can be estimated as follows (considering the compatibility of the section rotations in relation to the inertial moment of each part, due to the fact that the rotation of a section is considered proportional to its bending stiffness $E J$ )

5. $\quad \boldsymbol{M}_{\mathrm{c}}=\boldsymbol{M} \frac{b_{\mathrm{c}} S_{1}^{3} / 12}{J_{\mathrm{s}}}=\boldsymbol{M} \frac{\left(b_{\mathrm{c}} S_{1}^{3} / 12\right)}{\left(b_{\mathrm{c}} S_{1}^{3} / 12\right)+\left(b_{\mathrm{j}} S_{\mathrm{j}}^{3} / 12\right)}$

6. $\boldsymbol{M}_{\mathrm{j}}=\boldsymbol{M} \frac{b_{\mathrm{j}} S_{\mathrm{j}}^{3} / 12}{J_{\mathrm{s}}}=\boldsymbol{M} \frac{b_{\mathrm{j}} S_{\mathrm{j}}^{3} / 12}{\left(b_{\mathrm{c}} S_{\mathrm{l}}^{3} / 12\right)+\left(b_{\mathrm{j}} S_{\mathrm{j}}^{3} / 12\right)}$

On the other hand, $\boldsymbol{M}_{\mathrm{j}}$ can also be estimated from the normal forces $\left(\boldsymbol{N}_{\mathrm{j}}\right)$ as (see Figure 2)

7. $\boldsymbol{M}_{\mathrm{j}}=\boldsymbol{N}_{\mathrm{j}}\left(\frac{S_{\mathrm{l}}}{2}-\frac{S_{\mathrm{j}}}{3}\right)$

where

8. $\quad N_{\mathrm{j}}=N \frac{b_{\mathrm{j}} S_{\mathrm{j}}}{b_{\mathrm{c}} S_{\mathrm{l}}+b_{\mathrm{j}} S_{\mathrm{j}}}$

Combining Equations 6 and 7 yields

9. $\boldsymbol{M} \frac{b_{\mathrm{j}} S_{\mathrm{j}}^{3} / 12}{\left(b_{\mathrm{c}} S_{1}^{3} / 12\right)+\left(b_{\mathrm{j}} S_{\mathrm{j}}^{3} / 12\right)}=\boldsymbol{N} \frac{b_{\mathrm{j}} S_{\mathrm{j}}}{b_{\mathrm{c}} S_{\mathrm{l}}+b_{\mathrm{j}} S_{\mathrm{j}}}\left(\frac{S_{\mathrm{l}}}{2}-\frac{S_{\mathrm{j}}}{3}\right)$
Knowing the values of $\boldsymbol{M}$ and $\boldsymbol{N}$ at each section, which are determined from the previous step, the height of the joint section $S_{\mathrm{j}}$ can be estimated as the integer root of Equation 10 .

10.

$$
\begin{gathered}
\frac{N b_{\mathrm{j}}}{3} S_{\mathrm{j}}^{4}+\left(\boldsymbol{M} b_{\mathrm{j}}-\frac{\boldsymbol{N} S_{\mathrm{l}} b_{\mathrm{j}}}{2}\right) S_{\mathrm{j}}^{3}+\boldsymbol{M} b_{\mathrm{c}} S_{\mathrm{l}} S_{\mathrm{j}}^{2} \\
+\frac{N S_{1}^{3} b_{\mathrm{c}}}{3} S_{\mathrm{j}}-\frac{\boldsymbol{N} S_{1}^{4} b_{\mathrm{c}}}{2}=0
\end{gathered}
$$

Due to the fact that $S_{\mathrm{j}}$ at each joint is unknown at the beginning, an iterative procedure is applied with the assumption that $S_{\mathrm{j}}$ is firstly equal to the thickness of the lining section $S_{1}$. With the height of the joint section $S_{\mathrm{j}}$ obtained from Equation 10, after each calculation step, if $\boldsymbol{M}_{\mathrm{j}} /\left(b_{\mathrm{j}} S_{\mathrm{j}}^{2} / 6\right)>\boldsymbol{N}_{\mathrm{j}} / b_{\mathrm{j}} S_{\mathrm{j}}$ (which corresponds to the case in which the joint is partly opened), the above procedure is applied to determine the height of the joint part $S_{\mathrm{j}}$. On the other hand, $S_{\mathrm{j}}=S_{1}=S_{\text {total }}$. These $S_{\mathrm{j}}$ values at joints in the lining are then used to estimate the inertial modulus $\left(J_{\mathrm{s}}\right)$ and area $\left(A_{\mathrm{s}}\right)$ of the transversal section at each node along the tunnel perimeter, which are used in the next step of the iterative procedure. The iterative procedure is continued until convergence of the joint height $S_{\mathrm{j}}$ is obtained.

An advantage of the new SHRM over the HRM developed by Do et al. (2014a) is that it allows consideration of a reduced joint area (see Figure 3). It was impossible to consider this joint type directly in the HRM proposed previously (Do et al., 2014a).

\section{Case study: shield tunnelling for the Bologna-Florence railway line project}

Parameters from the Bologna-Florence railway line, part of the Italian high-speed rail network, were used to assess the performance of the new SHRM. In this study it is assumed that the behaviour of the soil and the tunnel structure is linearelastic. The properties of the soil and tunnel lining are given in Table 1.

In order to assess the performance of the SHRM, a simplified 3D numerical model was developed using the generalised finite-difference program Flac3D (Itasca, 2009). A 3D simulation of a tunnel supported by means of a segmental lining

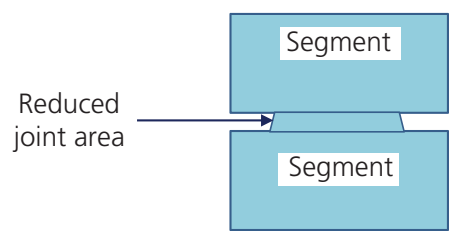

Figure 3. Decreased joint type 
Table 1. Section parameters at lining ring 582 (Croce, 2011)

\begin{tabular}{|ll|}
\hline Parameter & Value \\
\hline Soil properties & \\
Unit weight, $\gamma: \mathrm{kN} / \mathrm{m}^{3}$ & 17 \\
Young's modulus, $E: \mathrm{MPa}$ & 150 \\
Poisson's ratio, $v$ & $0 \cdot 3$ \\
Internal friction angle, $\phi$ : degrees & 37 \\
Lateral earth pressure factor, $K_{0}$ & $0 \cdot 5$ \\
Overburden, $H: \mathrm{m}$ & 20 \\
Properties of the tunnel lining & 35000 \\
Young's modulus, $E_{\mathrm{s}}: \mathrm{MPa}$ & $0 \cdot 15$ \\
Poisson's ratio, $v_{\mathrm{s}}$ & $0 \cdot 4$ \\
Lining thickness, $t: \mathrm{m}$ & $9 \cdot 4$ \\
External diameter, $D: \mathrm{m}$ &
\end{tabular}

was simulated in the simplified 3D numerical model. In addition, the new SHRM was also compared with the existing complex HRM developed by the authors (Do et al., 2014a). Detailed descriptions and evaluations of the performance of both the simplified 3D model using Flac3D and the existing complex HRM have been presented by Do et al. (2014a) and are therefore not repeated here.

Figure 4 shows the bending moment and normal forces induced in the tunnel linings. Without considering the spikes in the bending moment at the segmental joint locations, Figure 4(a) indicates that the bending moment results obtained by the new SHRM were in good agreement with those of the complex HRM and were more less the same as those obtained using the Flac3D model. As far as normal forces induced in the tunnel structure are concerned, Figure 4(b) shows good agreement between the results obtained with the complex HRM and the new SHRM. However, there was a significant difference between the shapes of the normal forces diagrams along the tunnel periphery obtained by the HRMs and Flac3D. This difference could be due to the fact that the methods do not consider soil behaviour in the same way: a continuous medium is assumed in Flac3D while, in the HRMs, soil action is considered by independent springs in each part of the beam elements. This indicates that several interactions cannot be taken into account by the subgrade reaction method, such as the load transfers resulting from arching effects. It should be noted that, compared with the Flac3D model, both the HRM and the SHRM slightly underestimated the normal forces. Caution is therefore necessary when using the HRM or SHRM for the design of tunnel linings. A decrease in normal forces generally causes a decrease of the allowable maximum bending moment induced in the tunnel lining. This combination of structural forces leads to a safer tunnel lining from the design point of view.

Due to movement of the tunnel lining towards the surrounding ground at the springline with angles $\omega$ of $90^{\circ}$ and $270^{\circ}$ in this study, reaction forces from the surrounding soil mass acting on the tunnel lining through springs placed at nodes along the

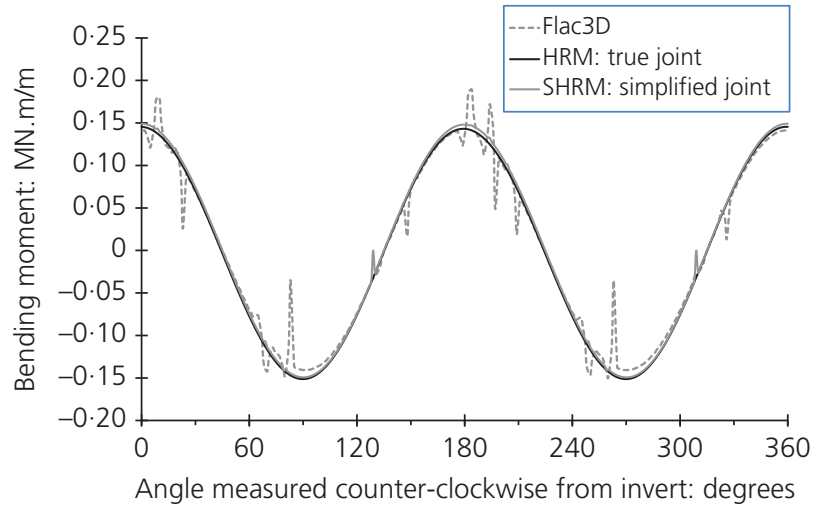

(a)

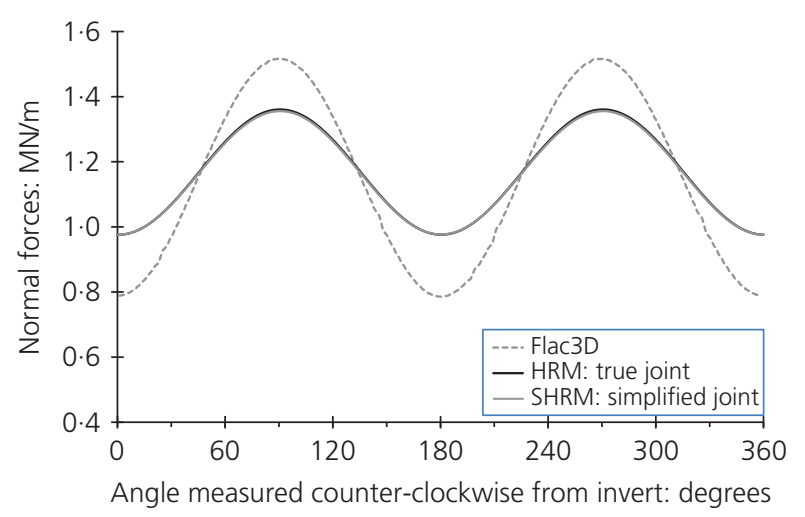

(b)

Figure 4. Comparison of (a) bending moments and (b) normal forces in the tunnel lining obtained using the SHRM, the complex HRM and Flac3D

tunnel section in the HRMs will develop. The compressive normal forces produced in the tunnel lining at these sections will therefore be transferred to the sections at which normal forces are currently smaller (at the crown and invert of the tunnel with angles $\omega$ of $90^{\circ}$ and $270^{\circ}$ in this study). Consequently, normal forces at these sections, which were originally small, will increase, as shown by the HRMs (Do et al., 2018).

The following comments can be made on the basis of the above analysis.

- The structural force results obtained using the SHRM were globally in good agreement with the results of the complex HRM and the numerical Flac3D model. However, this was not the case locally near the joint location.

- The influence of joints in segmental linings can be taken into consideration through the reduction of the transversal section and therefore through the inertial modulus of the lining. This simplified way of taking joints into account gives the same results as a more complex method (the case of a true joint). 


\section{Conclusions}

A new simplified approach to the HRM applied to a segmental tunnel lining has been presented and the adopted mathematical procedure detailed. The influence of segmental joints was considered directly using a reduction in the transversal section and therefore the inertial modulus of sections along lining rings, which are influenced by the presence of segmental joints. A specific implementation was developed using a finiteelement method framework. The SHRM allows the arbitrary distribution of segmental joints along a tunnel boundary to be taken into consideration.

A simplified 3D numerical model developed using Flac3D software and the existing complex HRM were used to assess the performance of the new SHRM. The numerical results presented in this paper show that the SHRM can be used to investigate the behaviour of a segmental tunnel lining instead of $3 \mathrm{D}$ numerical modelling.

\section{Acknowledgement}

This research is funded by the Vietnam National Foundation for Science and Technology Development (NAFOSTED) under grant number 105.08-2015.14.

\section{REFERENCES}

Arnau O and Molins C (2012) Three dimensional structural response of segmental tunnel linings. Engineering Structures 44: 210-221.

Blom CBM (2002) Design Philosophy of Concrete Linings for Tunnel in Soft Soils. PhD dissertation, Delft University, Delft, the Netherlands.

Croce A (2011) Analisi Dati di Monitoraggio del Rivestimento della Galleria del Passante Ferroviario di Bologna. Degree dissertation, Polytechnic of Turin, Turin, Italy (in Italian).

Ding WQ, Yue ZQ, Tham LG et al. (2004) Analysis of shield tunnel. International Journal for Numerical and Analytical Methods in Geomechanics 28(1): 57-91.

Do NA, Dias D and Oreste PP (2018) Numerical investigation of segmental tunnel linings-comparison between the hyperstatic reaction method and a 3D numerical model. Geomechanics and Engineering (in press), https://doi.org/10.12989/gae.2018.14.3.000. Do NA, Dias D, Oreste PP and Djeran-Maigre I (2013) 2D numerical investigation of segmental tunnel lining behaviour. Tunnelling and Underground Space Technology 37: 115-127.

Do NA, Dias D, Oreste PP and Djeran-Maigre I (2014a) A new numerical approach to the hyperstatic reaction method for segmental tunnel linings. International Journal for Numerical and Analytical Methods in Geomechanics 38(15): 1617-1632.

Do NA, Dias D, Oreste PP and Djeran-Maigre I (2014b) The behaviour of the segmental tunnel lining studied by the hyperstatic reaction method. European Journal of Environmental and Civil Engineering 18(4): 489-510.

Duddeck H and Erdmann J (1982) Structural design models for tunnels: Tunnelling 82. In Proceedings of the 3rd international symposium, Brighton. IMM, London, UK, pp. 83-91.

Einstein HH and Schwartz CW (1979) Simplified analysis for tunnel supports. Journal of Geotechnical Engineering 105(4): 499-518.

Huebner KH, Dewhirst DL, Smith DE and Byrom TG (2001) The Finite Element Method for Engineers. Wiley, New York, NY, USA.

Itasca (2009) FLAC Fast Lagrangian Analysis of Continua, Version 4.0. User's Manual. Itasca, Minneapolis, MN, USA.

Lee KM, Hou XY, Ge XW and Tang Y (2002) An analytical solution for a jointed shield driven tunnel lining. International Journal of Analytical and Numerical Methods in Geomechanics 25(4): 365-390.

Monforton GR and Wu TS (1963) Matrix analysis of semi-rigidly connected frames. Journal of Structural Engineering, ASCE 89(6): $13-42$.

Muir Wood AM (1975) The circular tunnel in elastic ground. Géotechnique 25(1): 115-127, https://doi.org/10.1680/geot.1975.25. 1.115 .

Naggar El and Hinchberger SD (2008) An analytical solution for jointed tunnel linings in elastic soil or rock. Canadian Geotechnical Journal 45(11): 1572-1593.

Oreste PP (2007) A numerical approach to the hyperstatic reaction method for the dimensioning of tunnel supports. Tunnelling and Underground Space Technology 22(2): 185-205.

Takano YH (2000) Guidelines for the design of shield tunnel lining. Tunnelling and Underground Space Technology 15(3): 303-331.

Zhang D, Huang H, Phoon KK and Hu Q (2014) A modified solution of radial subgrade modulus for a circular tunnel in elastic ground. Soils and Foundations 54(2): 225-232.

\section{How can you contribute?}

To discuss this paper, please email up to 500 words to the editor at journals@ice.org.uk. Your contribution will be forwarded to the author(s) for a reply and, if considered appropriate by the editorial board, it will be published as discussion in a future issue of the journal.

Proceedings journals rely entirely on contributions from the civil engineering profession (and allied disciplines). Information about how to submit your paper online is available at www.icevirtuallibrary.com/page/authors, where you will also find detailed author guidelines. 